\title{
Educación del cuerpo y política: concepciones de raza, higienismo y eugenesia en la Educación Física Argentina
}

Eduardo Lautaro Galak

\begin{abstract}
Resumen: La relación entre cuerpo y política es central en la historia de las sociedades. En este caso particular se analiza esta relación en los discursos de las políticas estatales centralizadas en Argentina sobre la Educación Física, a partir de repensar históricamente las concepciones en torno a la idea de cómo educar los cuerpos para mejorar la raza. Para ello, se observa el pasaje de las retóricas higienistas de finales del siglo XIX y principios del XX a las interpretaciones eugenésicas de las décadas de 1920 y 1930, y cómo ello configura algunas de las argumentaciones de las prácticas disciplinares actuales.
\end{abstract}

Palabras clave: Cuerpo. Política. Eugenesia. Educación.

\section{Palabras iniciales}

Pensar es siempre una tarea colectiva. En este caso, una tarea a ser realizada entre quien escribe y quien lee, mediada por un suelo común de creencias -sin que ello signifique necesariamente común acuerdo-. Por ello, para desarrollar las ideas que en este escrito se trabajan, se comienza por explicitar el suelo donde se edifica el andamiaje teórico que en los párrafos venideros se construye.

En principio, se parte de la siguiente premisa: todo discurso sobre la Educación Física - o toda "doctrina", para expresarlo en los términos "nativos" en que antaño se los reconocía -, tiene necesariamente concepciones sobre "política", sobre "sujeto" y

\footnotetext{
Universidade Federal de Minas Gerais (UFMG), Faculdade de Educação. Belo Horizonte, MG, Brasil; Universidad Nacional de La Plata (UNLP). Programa de Pos-grado en Ciencias Sociales. La Plata, Argentina. E-mail: eduardogalak@gmail.com
} 
sobre "cuerpo", aun cuando no estén explicitadas o sean entendidas en términos latos. Esto supone concebir que para comprender la episteme disciplinar de cada época es preciso interpretar acerca de los modos de organización de las sociedades - siendo la educación un modo de garantizar su reproducción -, de las personas que aprenden y enseñan, que participan en la vida de la Educación Física, y respecto del "material" (físico y simbólico) con el cual se trabaja, así como del movimiento. En síntesis, en el embrague entre los componentes de la triada política-sujeto-cuerpo pueden entreverse las concepciones contextuales de "cada" Educación Física. ${ }^{1}$

En este caso, la tarea se centra especialmente en la relación entre "cuerpo" y "política", o, expresado en términos más concretos, en las formas en que los discursos oficiales en Argentina concibieron la educación de los cuerpos en general, y la Educación Física en particular. De hecho, puede afirmarse que los discursos disciplinares han estado constantemente atados a los designios de las políticas estatales (GALAK, 2012), aun cuando históricamente se la presenta como una asignatura pedagógica a-política, que despolitiza sus prácticas, sus contenidos y los cuerpos con los que ejerce su oficio.

En efecto, la Educación Física ha sido objeto de "la" política, ha quedado presa del poder centralizado coyuntural sin lograr generar alternativas universales "relativamente autónomas" a éste. Epistemo-metodológicamente ello implica centrarse en analizar aquellos discursos que trascendieron, es decir, que cumplieron con los siguientes tres requisitos: que hayan excedido la coyuntura de su producción, que pretendieron (y de alguna forma lo consiguieron)

\footnotetext{
${ }^{1}$ Un análisis pormenorizado de cómo estas tres categorías conforman el nomos del campo de la Educación Física argentina puede leerse "Del dicho al hecho (y viceversa). El largo trecho de la construcción del campo de la formación profesional de la Educación Física en Argentina. Legalidades, legitimidades, discursos y prácticas en la institucionalización de su oficio entre finales del siglo XIX y el primer tercio del XX" (GALAK, 2012). De hecho, el material documental utilizado para este artículo es retomado de aquella investigación, en la cual se estudiaron como fuentes historiográficas artículos y noticias pedagógicas de revistas especializadas, libros, folletos, resoluciones gubernamentales, entre otras, acerca de la formación profesional en Educación Física en Argentina, desde finales del siglo XIX hasta la década de 1930.
}

Movimento, Porto Alegre, v. 20, n. 4, p. 1543-1562, out./dez. de 2014. 
posicionarse como dominantes y que se postularon como "la" alternativa nacional, que hablen en nombre de "la" educación del cuerpo argentina.

Establecido este suelo de creencias comunes, la propuesta es pensar la relación entre "doctrinas" de la Educación Física con las políticas estatales y sus retóricas, a partir de analizar tres momentos particulares de la historia disciplinar argentina: primero, los orígenes de la Educación Física argentina, en dónde ese vínculo responde a las exigencias del higienismo y la cientificidad; segundo, en las décadas de 1920 y 1930, instancia en la que se produce un claro intento por realizar una interpretación de los pensamientos higienistas como eugenistas, con el definitivo ingreso de la psicologización y biometrización de las prácticas disciplinares; y tercero, la traducción contemporánea de los legados tradicionales. En otras palabras, lo que se analiza es el pasaje entre dos modos políticos que, aun cuando no estuvieron exentos de disputas en su interior ni resultaron uniformes, configuraron técnicas de intervención sobre los cuerpos a través de la Educación Física, las cuales de diferentes maneras perduran hasta la actualidad.

\section{2 “LA GIMNÁSTICA CIVILIZARÁ A LOS TOBAS”}

En 1886 Domingo Faustino Sarmiento inmortalizó esta frase que no sólo expone su pensamiento respecto a la educación de los cuerpos sino que resume gran parte del ideario de quienes pensaron el país a fines del siglo XIX (CANESSA, 1946; AISENSTEIN; SCHARAGRODSKY, 2006). La manera de comprender la enseñanza de las actividades motrices por parte de la "generación del ochenta" signó a la educación física, en minúsculas, ${ }^{2}$ en un doble aspecto. Por un lado, como un complemento de todo tipo de instrucción, respetando así el legado "integralista" con que la pedagogía fundamentó la educación pública estatal. Esto implicó

\footnotetext{
${ }^{2}$ Se hace esta aclaración para distinguir aquellos sentidos generales usados para referirse a la educación física -donde gimnástica, calistenia, actividades físicas o ejercitaciones militares entre otros nombres que resultaban sinónimos en la jerga finisecular-, de la especificidad que encierra la disciplina Educación Física, "en mayúsculas" (GALAK, 2012).
}

Movimento, Porto Alegre, v. 20, n. 4, p. 1543-1562, out./dez. de 2014. 
que además de obligatoria, gratuita y laica, la pedagogía argentina reprodujera la herencia de la tríada spenceriana que propone que toda educación debe ser intelectual, moral y física (GALAK, 2013). De esta manera, la justificación para realizar actividades físicas se argumenta en que permite una descarga de energía que favorece la quietud necesaria para los aprendizajes intelectuales, al mismo tiempo que pone en práctica los sentidos morales - parafraseando a Thompson (1995), una suerte de "economía moral de los cuerpos", fundamentalmente a través de los juegos al aire libre, las marchas militares y las rondas escolares.

El otro aspecto a destacar es que, gracias a las posibilidades que brinda un Sistema Educativo centralizado capaz de transmitir un mismo conocimiento universal simultáneamente a todos los individuos - herencia de la pedagogía comeniana -, las actividades físicas escolares resultaron un recurso significativo para la difusión de valores y símbolos patrios, y con ello una importante herramienta de civilización, un elemento de progreso social que separa al hombre de la barbarie. Sin embargo, aun cuando universal, no todo conocimiento significa un contenido escolar: para que efectivamente sea "civilizador" es necesario que esté científicamente probado, o por lo menos que esté argumentado en lenguaje científico. ${ }^{3}$

De esta manera, en esa idea de educar como modo de "civilizar" está contenida la concepción de porvenir, de progreso de la Patria y de la raza, supeditados a la transmisión de la racionalidad moderna y a la enseñanza de conocimientos argumentados científicamente, cerrándose así el círculo teórico que piensa a la educación como garantía de reproducción de la política. De allí que las nociones de civilización, de progreso, de ciencia y de educación se fundieron como sinónimos en las retóricas escolarizantes.

\footnotetext{
${ }^{3}$ Vale realizar aquí tres aclaraciones: una, que no necesariamente todo conocimiento transmitido estaba científicamente probado pero sí "científicamente hablado", es decir, que reproducía la retórica de la ideología cientificista de la época; dos, que la referencia a "científico" en este contexto histórico remite generalmente a "ordenamiento racional" de las clases; y tres, que cuando se dice "ciencia" se alude a la lengua utilizada por la pedagogía finisecular: como afirman Emilio Tenti Fanfani (2011) e Inés Dussel (2001), los discursos originarios del Sistema Educativo argentino están "hablados" casi exclusivamente en lenguaje científico-positivista.
}

Movimento, Porto Alegre, v. 20, n. 4, p. 1543-1562, out./dez. de 2014. 
Resultado de esta herencia pedagógica, estos conceptos constituyeron el núcleo argumental de la episteme de las primeras formas institucionalizadas de entender a las actividades físicas, dejando sus huellas hasta la actualidad: como un legado insoportablemente sostenido hasta nuestros días, parece ser que si no es razonado en términos científicos, los conocimientos que transmite la escuela en general, y la Educación Física en particular, no tienen sentido.

Como lo grafica la afirmación de Enrique Romero Brest, (1914, p. 8) reputado como el padre de la disciplina en Argentina y quien creara el "Sistema Argentino de Educación Física" como retórica legitimadora de las principales argumentaciones oficiales que se utilizaron durante el primer tercio del siglo $\mathrm{XX}$ : "[...] todo lo que pertenece en realidad a la escuela debe llevar el sello científico" De hecho, no resulta casual que el propio Romero Brest considerara a Sarmiento y a sus ideas como "un símbolo, una idea fundamental en el proceso de nuestra nacionalidad":

Sarmiento es el espíritu europeo, civilizado, humanitario, luchando contra las fuerzas brutas, oscuras y salvajes de los bosques y de las pampas americanas. Sarmiento es el espíritu del progreso, de la nacionalidad, de la humanidad, de la patria grande construida, en oposición a la toldería, al gaucho, al indio, al oscurantismo, a la anarquía. Sarmiento representa este gran factor en la nacionalidad argentina: la idea de la civilización (ROMERO BREST, 1911, p. 41).

Ahora bien, ¿qué se entendía por "cuerpo" en el contexto de los discursos fundacionales de la escolarización estatal? Cuerpo significaba casi exclusivamente la naturaleza física, material, tangible, a la vez que es, como el sujeto, un todo indisociable, analíticamente desglosable en partes pero a fin de cuentas "integral".

Sin embargo, entender al cuerpo de este modo resulta contradictorio con la contemporánea polaridad civilizaciónbarbarie, que ubica del lado del primer polo a la educación y en el

Movimento, Porto Alegre, v. 20, n. 4, p. 1543-1562, out./dez. de 2014. 
contrario a la naturaleza. Entonces ¿cómo educar a la naturaleza? ¿Cómo "Educación Física” si la naturaleza es ineducable?

La respuesta disciplinar a estas preguntas resultó ser que la Educación Física constituyó como su objeto, más que efectivamente al cuerpo, al movimiento. De allí que los manuales finiseculares y de comienzos del siglo XX se dediquen a describir ejercitaciones físicas, centrando su atención en las formas correctas e higiénicas (científicas) de ejecución. De hecho, no resulta casual que la calistenia constituyera la base de la denominada "gimnasia militar argentina" - tal como llamó Sarmiento al espacio curricular encargado de transmitir ejercicios físicos -, la cual homogeneiza el movimiento con justificaciones fisiologistas. Aunque en rigor de verdad de "argentina" tenía sólo el contexto de su ejecución: la propuesta oficial recupera de la corriente gimnástica alemana tanto la utilización de aparatos cuanto el sentido higiénico de su práctica, en tanto que de la italiana rescata el ideario de formar el carácter a través de enseñanzas patrióticas (BERTONI, 1996; SARAVÍ RIVIERE, 1985).

Si como sostiene Sarmiento (1900, p. 16) la intención de la escuela no es formar "[...] ni enanos ni sabios, ni atletas sanguinarios o idiotas", entonces la gimnasia es un contenido altamente civilizador ya que reúne la instrucción corporal, el descanso intelectual y la higiene moral. De esta manera, las primeras formas de educación del cuerpo institucionalizadas debían ser - y así lo fueron - "pragmáticas", útiles a finalidades de superior interés, estar al servicio de los designios de la política.

Este posicionamiento sarmientino reafirma uno de los objetivos centrales de la educación estatal y uno de los sentidos primigenios que justificaron la inclusión de las actividades físicas en las escuelas: la búsqueda del porvenir de la raza argentina, entendiendo el perfeccionamiento de ese "crisol de razas" no en términos de intervención en la herencia biológica sino como producto del mejoramiento de las condiciones de origen. Pues como afirma el propio Sarmiento, esta asignatura escolar tiene por

Movimento, Porto Alegre, v. 20, n. 4, p. 1543-1562, out./dez. de 2014. 
misión constituirse en "el germen de la institución del porvenir" (SARMIENTO, 1900, p. 278).

De hecho, puede establecerse que la pretensión de mejorar la "raza argentina" a través de las ejercitaciones físicas proviene de la influencia que tuvieron sobre la "generación del ochenta" los postulados pedagógicos del filósofo inglés Herbert Spencer, quien sostenía que el problema educativo más urgente era instruir a los padres, para favorecer las futuras generaciones. En tanto que la principal misión de la escolarización según su parecer consistía en intervenir en un porvenir mejor, para perfeccionar la raza, para fortalecer la política (GALAK, 2013). Este nudo epistémico tiene consecuencias prácticas hasta la actualidad: la Educación Física porta como signo la búsqueda por el perfeccionamiento de la raza (GALAK, 2014) ${ }^{4}$, aunque no siempre ello significó lo mismo.

En síntesis, estos sentidos que se desprenden de la frase de Sarmiento signan a la Educación Física, con mayúsculas - es decir, como la disciplina institucionalizada que reconocemos en la actualidad, fundamental pero no exclusivamente escolar -, desde sus orígenes hasta la actualidad: "la gimnástica civilizará a los Tobas" (SARMINETO, 1900, p. 278) condensa el ideario de la época de que la transmisión de actividades físicas debe ser complemento de las instrucciones intelectuales y morales, al mismo tiempo que debe perseguir "la" civilización a través de la enseñanza de contenidos científicamente argumentados, en los que se entremezcla la transmisión de conceptos higiénicos con la búsqueda del progreso y fortaleza de la raza argentina.

\section{3 “Educar es eugenizar”}

Estos postulados fundacionales de la episteme de la Educación Física funcionaron cuasi invariablemente hasta el inicio del segundo cuarto del siglo $\mathrm{XX}$, cuando se produce una reconfiguración

${ }^{4}$ GALAK, Eduardo. 'La educación física persigue el perfeccionamiento de la raza'. Políticas públicas, salud, eugenesia y educación de los cuerpos. In: FRAGA, A.; GOMES, I.; CARVALHO, Y. As práticas corporais no campo da saúde. En prensa, 2014. v.2.

Movimento, Porto Alegre, v. 20, n. 4, p. 1543-1562, out./dez. de 2014. 
conceptual que impacta sobre la educación de los cuerpos, aún hasta la actualidad: a las argumentaciones disciplinares sobre la raza en sentido higienista como "identidad del grupo social", se le incorporaron lecturas eugenésicas, ${ }^{5}$ interpretando al cuerpo (biológico, especie, étnico) como objeto de intervención política, principalmente en términos de salud.

Esta afirmación requiere dos aclaraciones. Por un lado, que aun cuando reconocidos historiadores del campo refieran como una de las bases de la disciplina a la eugenesia, no deben confundirse los discursos de progreso de la raza presentes en el ideario ochentista con las políticas eugenésicas propiamente dichas. De hecho, para el contexto latinoamericano el movimiento eugenésico puede ser identificado recién a partir de la década de 1910, el cual no se presentó en absoluto como homogéneo en su interior pero sí con una característica común: los discursos eugenésicos se adueñaron de sentidos sobre lo que significaba la "raza" (argentina), legitimando modos de intervención política sobre las razas argumentados en términos eugenésicos y estableciendo como retórica una sinonimia entre raza y eugenesia. ${ }^{6}$

Por otro lado, si bien es un concepto asociado a la barbarie nazi como su máxima expresión, con su totalitarismo basado en la discriminación racial, en la profilaxis social y en la justificación médico-biológica de la calipedia - la quimérica pretensión de procurar la calidad de la prole -, la eugenesia no necesariamente remite a algún tipo de violencia o sacrificio, por lo menos no en términos físicos. En efecto, en contraposición de la "negativa"

\footnotetext{
${ }^{5}$ Traducción del griego "buenos genes" o "buena reproducción", la eugenesia se constituye como un movimiento político-filosófico que se desarrolló fundamentalmente a partir de la lectura que hace Francis Galton -quien acuña el término en 1883- de los postulados de su primo, Charles Darwin, sobre la evolución de las especies y la selección "natural", y de la relectura que hace Herbert Spencer con su "darwinismo social".

\begin{abstract}
${ }^{6}$ Para profundizar sobre las distintas vertientes iberoamericanas sobre la eugenesia puede leerse Cuerpo, biopolítica y control social. América Latina y Europa en los siglo XIX y XX de Marisa Miranda y Álvaro Girón Sierra (2009), Darwinismo social y eugenesia en el mundo latino y Políticas del cuerpo. Estrategias modernas de normalización del individuo y la sociedad de Gustavo Vallejo y Marisa Miranda $(2005 ; 2007)$. En tanto para observar especificidades del caso argentino véase Una historia de la eugenesia: Argentina y las redes biopolíticas internacionales también de Vallejo y Miranda (2012).
\end{abstract}

Movimento, Porto Alegre, v. 20, n. 4, p. 1543-1562, out./dez. de 2014. 
comúnmente asociada al nazismo, en la Argentina primaron las versiones "positiva", preocupada por una procreación sana a través de promover la reproducción de ciertos caracteres reconocidos como socialmente deseables, y "latina", que remite a la influencia de la biotipología italiana y su afán por medir y clasificar biotipos (VALLEJO; MIRANDA, 2005; 2007). ${ }^{7}$

Por caso, la "eugenesia positiva" tuvo su impacto en diversos órdenes: en las investigaciones biológicas y genéticas para favorecer las políticas públicas de fertilidad o de disminución de la mortandad infantil, en el campo de farmacológico y médico, con el consecuente desarrollo de lo que Roberto Esposito (2007) denomina el "paradigma inmunitario" en la tensión entre "bio" y "tanatopolítica", o en el ámbito del Derecho, con la puesta en práctica de leyes eugenésicas que regulan los matrimonios - exámenes pre-matrimoniales que aún hoy siguen siendo obligatorios - o con el impedimento de ingreso al país a delincuentes reales o potenciales - argumentando razones raciales amparadas en los estudios del positivismo criminológico sobre la determinación de la conducta criminal, entre los que se destacan las teorías de Cesare Lombroso sobre la detección y clasificación de delincuentes, lo cual llegó a límites "negativos" cuando se esterilizaron presos.

Pero sin lugar a dudas resultaron la educación y las campañas higienistas los principales vehículos para su difusión, constituyéndose la Educación Física en un recurso clave para transmitir masivamente hábitos sanos: a fin de cuentas, como sostiene Renato Kehl (1929, p. 1) “educar es eugenizar”. Este movimiento epistémico supuso que el cuerpo cobre una importancia

\footnotetext{
"Vale mencionar que la "Sociedade Eugênica de São Paulo", creada en 1918 -la primera en su tipo en Latinoamérica-, incorporaba a esta división la "eugenesia preventiva", la cual se ocupa de la conquista de factores ambientales "disgenésicos" a través de campañas públicas de saneamiento (STEPAN, 1991). Estas ideas deben su institucionalización a Renato Ferraz Kehl, quien puede ser identificado como el principal eugenista brasilero, con una vasta bibliografía que incluye referencias a la Educación Física, y quien fuera uno de los autores más citados por los eugenistas argentinos, fundamentalmente por su relación con Víctor Delfino y Alfredo Fernández Verano, aún cuando los discursos de Kehl estén mayoritariamente asociados a sentidos eugenésicos "negativos" (SILVA, 2008; KINOSHITA; PIMENTA, 2013).
}

Movimento, Porto Alegre, v. 20, n. 4, p. 1543-1562, out./dez. de 2014. 
inusitada como blanco de las políticas centralizadas eugenésicas, provocando que "lo físico" deje de lado su histórico papel de complementariedad de "lo intelectual" y "lo moral", para ocupar un rol articulador de las enseñanzas de una moral sana y de una intelectualidad correcta.

Ello produjo tres consecuencias que signan la Educación Física, aún hasta la actualidad.

Primera, que es justamente entre las décadas de 1920 y 1930 que la disciplina muda su concepción sobre el "cuerpo" en dos sentidos emparentados, que redundan en el pragmatismo al cual parece condenada. Por un lado, los discursos del campo reflejan un cambio en la forma de entender al cuerpo como naturaleza, para referirlo como una máquina humana. Lo cual encarna una profundización en la escisión entre cuerpo y sujeto, ubicando al cuerpo en el lugar de objeto y provocando consecuentemente que sea considerado cosa útil y blanco de intervención (VAZ, 1999). Si bien tal como explica Jacques Gleyse (2011) la metáfora del cuerpo como máquina aparece desde comienzos del siglo XIX, los documentos de la época resignifican los sentidos originarios, generando la penetración de estudios sobre biomecánica al ámbito educativo, la confusión de lo anátomo-fisiológico con lo motor y la medición de parámetros físicos y motrices, así como del tiempo, como recursos pedagógicos y de evaluación. En definitiva, una biometrización del cuerpo y del sujeto, características que reafirman el postulado que el objeto de la Educación Física es, antes que el cuerpo, el movimiento y su técnica.

Por el otro, vuelve a aparecer constantemente en los discursos "doctrinarios" la referencia a la frase de Juvenal "mens sana in corpore sano", lo cual significa la retórica de la subordinación del cuerpo a la mente, como en la tradicional tríada integralista spenceriana, pero también la resignifica al supeditar la mente y el cuerpo a la salud. Ambos sentidos denotan que se subsume el cuerpo a la tecnocracia del saber (biomédico), simultáneamente que se produce un corrimiento de la enseñanza intelectual como

Movimento, Porto Alegre, v. 20, n. 4, p. 1543-1562, out./dez. de 2014. 
panacea de los problemas sociales, puesto que ahora tanto la mens como el corpore dependen de "la" salud como remedio de todos los males.

De allí que desde la década de 1920 la salud comience a gobernar los discursos de la Educación Física, materia representante de la transmisión de hábitos higiénicos y saludables en las escuelas, cuestión que trae como consecuencias que se (mal)interprete al profesional de la disciplina como "agente de salud" o que la Educación Física sea vehículo de políticas de salubridad pública en su sentido más amplio, como que sea objeto de campaña para resolver el "esencial problema" de la masturbación (SANCTIS, 1934) o que constituya "[...] base de la defensa civil contra el comunismo" (FRESCO, 1940, p. 2).

El segundo efecto de la incorporación de los discursos eugenésicos puede hallarse en la importancia que cobraron las argumentaciones psicologistas. Eso se traduce en que, de allí en adelante, hablar de pedagogía en el marco de la Educación Física (aunque no exclusivamente) es hablar de psico-pedagogía. En efecto, no es casualidad que quienes plantearon el mejoramiento de la raza argentina en términos eugenésicos y que pusieron al cuerpo en el centro de la escena hayan sido los mismos que incorporaron a la disciplina la psicologización de lo biológico y la biometrización del cuerpo y de los movimientos.

Específicamente en el ámbito de la Educación Física, ello signó como marca disciplinar la sinonimia entre naturaleza, dotes y talento, o lo que es lo mismo, dejó como huella pedagógica el determinismo de la individualización biológica: esto produjo que la enseñanza sea considerada una responsabilidad política colectiva, en tanto que el éxito o el fracaso del aprendizaje sea asunto de la naturaleza individual.

Esta cuestión de la individualización biológica producto del ingreso de discursos eugenistas y psicologistas a la disciplina, sumado al histórico rol higienista de la Educación Física, generaron que: a) como se dijo, se confunda a sus docentes con

Movimento, Porto Alegre, v. 20, n. 4, p. 1543-1562, out./dez. de 2014. 
potenciales "agentes de salud" y b) se equivoque lo pedagógico con lo psico-pedagógico, pero también que c) se embraguen las nociones de capacidad motora, talento y habilidad, biologizando e individualizándose sus concepciones y d) que, en definitiva, en el contexto de la Educación Física disciplinar, pedagogizar e higienizar resulten sinónimos.

De hecho, este puede ser el único punto en común entre las dos doctrinas que se disputaron los sentidos disciplinares durante el primer tercio del siglo XX: tanto la postura cívico-pedagógica conocida como "romerista" cuanto aquellos "militaristas" que proponían disciplinar e instruir antes que educar, adhirieron a distintas corrientes eugenésicas y promocionaron la incorporación de saberes ligados a la psicología, especialmente las corrientes evolutiva y conductista. Así, entre los miembros de la principal institución eugenésica, la "Asociación Argentina de Biotipología, Eugenesia y Medicina Social”, pueden hallarse "romeristas" como el propio Romero Brest - quien en el discurso de despedida como director del Instituto Nacional promulgaba una Educación Física eugenésica (ROMERO BREST, 1933) -, así también como su propio hijo Enrique Carlos y Juana Alzú, en tanto que entre los "militaristas" pueden encontrarse Gofredo Grasso - referencia médica de las instituciones militares - y hasta un joven Alejandro Amavet - aún en las fuerzas armadas, quien en la década de 1950 y 1960 se constituye en el principal impulsor de la Educación Física en la Universidad Nacional de La Plata, sin abandonar su "humanismo eugenésico"-. Junto con estas personalidades de la disciplina pueden mencionarse médicos de renombre como Mariano Castex, Mariano Barilari, Arturo Rossi, Octavio López, Gregorio Araoz Alfaro, Eugenio Galli, Carlos Bernaldo de Quiros, figuras influyentes de instituciones deportivas como César Vázquez, pedagogos reconocidos como Pablo Pizzurno y psicologistas y pedagogos psicologistas como Ángel Graffigna o Víctor Mercante - responsable de la "Sección Pedagógica" de la Universidad platense, base de la actual "Facultad de Humanidades y Ciencias de la Educación". Por citar sólo un ejemplo de la intrincada relación entre profesionales de

Movimento, Porto Alegre, v. 20, n. 4, p. 1543-1562, out./dez. de 2014. 
diversos órdenes y con diferentes posturas pero que comulgaron con el ideario eugenésico y psico-pedagogicista, puede indicarse la promoción en 1933 de la "ficha biotipológica ortogenética" para las escuelas bonaerenses, las cuales - promovidas por Mercante y Rossi y confeccionadas con ayuda de Romero Brest (INAUGURACIÓN..., 1934) - se proponían clasificar, seguir y controlar psico-pedagógicamente para establecer biotipos de alumnos, reproduciendo las lógicas eugenésicas y biotipológicas del italiano Nicola Pende (LAS FICHAS..., 1933; PENDE, 1933; 1934; 1935). En efecto, la conjunción entre postulados eugenésicos, biotipológicos y psicologicistas tuvo una gran influencia en la disciplina: la medición, clasificación y evaluaciones en las clases de Educación Física es herencia de estos discursos y de la retórica del mejoramiento racial.

Tercera consecuencia: debido a la coyuntura cultural, no resulta casual que en este contexto se produzca un importante cambio en los principales contenidos de la Educación Física: las décadas de 1920 y 1930 significaron el momento de la definitiva incorporación de los deportes a la Educación Física, contenido que con el correr de los años gana progresivamente espacio curricular, desplazando a las gimnasias y los juegos al aire libre. Además de haber sido favorecido por representantes de los principales clubes de elite porteño subidos al clima de época de la "Década infame", la razón de porqué los deportes ocuparon un lugar central entre los contenidos de la Educación Física se puede explicar por un beneficio recíproco: el deporte le sirvió a la disciplina como método de masificación de la creencia que el hábito de practicar actividades físicas trae de por sí una vida saludable, así como la incorporación de los deportes como contenido significó la decisiva aceptación social de las prácticas deportivas, en un contexto donde se debatía el pasaje del amateurismo con sus valores humanistas al profesionalismo liberal capitalista. ${ }^{8}$

\footnotetext{
${ }^{8} \mathrm{Al}$ respecto puede leerse el libro de Próspero Alemandri Moral y deporte (1937) así como la Revista "El Deporte y la Vida", publicación conjunta del Comité Olímpico Argentino y de la Confederación Argentina de Deportes realizada entre 1935 y 1939, dónde se difunde el "deportismo" como modo de vida, contando entre sus principales escribas a Alemandri, a Romero Brest y a Grasso, entre otros.
}

Movimento, Porto Alegre, v. 20, n. 4, p. 1543-1562, out./dez. de 2014. 


\title{
4 La panacea de cuerpos despolitizados o hacia una (re) politización de los cuerpos
}

\author{
Que cosa fuera, que cosa fuera la maza sin cantera, \\ un amasijo hecho de cuerdas y tendones, \\ un revoltijo de carne con madera, \\ un instrumento sin mejores pretensiones
} (RODRIGUEZ DOMINGUEZ, 1979)

Si bien el coqueteo con las políticas eugenésicas no implicó una adopción total por parte de la disciplina de todas sus ideas, sí manifiesta que ese contacto superficial con las mismas en una coyuntura determinada e identificable signó a la Educación Física de maneras que perduran con fuerza hasta la actualidad. La razón de porqué este ideario tuvo pregnancia puede ser explicada por el hecho que apoyarse en éste significó una manera de posicionarse como disciplina, no sólo en el campo educativo sino a nivel social en general.

Supeditando sus discursos a un orden político superior, en nombre de la educación del cuerpo se ha pretendido instruir ciudadanos moralmente sanos a partir de hacer foco en la técnica del movimiento y en la utilidad de su acción, objetivando al sujeto y al cuerpo como físico, naturaleza y biología.

Ahora bien, ¿qué implica pensar la Educación Física en el contexto de concebir la intervención sobre el cuerpo como progreso de la raza? Esta centralidad de la educación del cuerpo, ese corrimiento de lo intelectual a lo físico que muestran los discursos producidos desde el segundo cuarto del siglo XX y ese relativo éxito que tuvieron las campañas higienistas y de salubridad pública que pusieron en un lugar de privilegio a la disciplina, ¿supuso también una profundización en la construcción de la identidad de la Educación Física, de sus teorías y aún de sus prácticas? En definitiva, ¿se produjo un desarrollo de la política que compromete educar al cuerpo? 
Claramente, y a la luz de la historia, la respuesta es negativa. La ilusión de que la Educación Física trabaja con cuerpos despolitizados es constitutiva de la disciplina, aun cuando a cada paso de su historia la pedagogía politizó los cuerpos. Precisamente, es la política la que le otorga los sentidos y palabra al cuerpo, aún con su inefabilidad. ${ }^{9}$ Eso es ineludible.

Empero, como reproductores de esos sentidos, cabe interpelar en tanto educadores del cuerpo qué política se transmite. Por ello se proponen una serie de cuestionamientos hacia una (re)politización de los cuerpos.

Primero, ¿es posible una Educación Física que se salga de los discursos estatales, que se emancipe de los designios de "la" política? Aun cuando como sostienen Raumar Rodríguez y Cecilia Seré (2013) la jerga pedagógica ha provocado un vaciamiento conceptual y un desgaste ideológico de esta noción, aun cuando ésta no puede "venir de afuera", no se la pueda planificar, evaluar e incluso enseñar, la emancipación de los discursos disciplinares respecto de la política estatal se presenta como una de las vías para romper definitivamente con el legado psico-biologicista en el que parece haberse sumido a la Educación Física desde el segundo cuarto del siglo XX. Emanciparse, eso sí, sin pretensiones de una autonomía - o mediante una "autonomía relativa" -, sin caer tampoco en el reduccionismo individualista que supone la enunciación, definición y delimitación de la identidad - problemática característica de los discursos del campo fundamentalmente desde la década de 1990 en adelante. Emancipación que implica el constante recuerdo de la posición subjetiva del deseo, mediada pero no determinada por las lógicas objetivas propias de toda práctica social, como la Educación Física.

Segundo, ¿es posible una Educación Física no necesariamente científica? ¿Cómo construir una educación de los cuerpos que no

${ }^{9} \mathrm{Como}$ en el caso de los habitus en sentido bourdieuano, concebir que el cuerpo o las prácticas corporales son objetos naturales o naturalizados implica comprender que son algo (supuestamente) impensado, inefable e ingobernado, cuando, por el contrario, el lenguaje mudo del cuerpo es eminentemente político (GALAK, 2010).

Movimento, Porto Alegre, v. 20, n. 4, p. 1543-1562, out./dez. de 2014. 
esté argumentada por los conceptos canónicos de "la" ciencia y aquellos tradicionales de la disciplina? La alternativa se encuentra en romper aquella asociación entre ciencia, civilidad, progreso y educación que las funde en sinonimias y que lleva a tomar como objeto de la ciencia y de la educación al cuerpo y al sujeto.

Por último, ¿es posible una Educación Física que no esté argumentada en términos psico-pedagógicos? Afirmar que la pedagogía para la Educación Física es psico-pedagogía es decir que la disciplina por este camino está condenada a remitir al cuerpo a su pura biología y a la individualización biológica que determina que en última instancia sea "problema" del alumno aprender, ocultando así la política de educar los cuerpos. Más aún, mediante este camino la Educación Física enseña los límites de sus prácticas: dividiendo sus enseñanzas según hasta dónde (supuestamente) se puede aprender de acuerdo con la biología del alumno o su edad madurativa, se reproduce esta tradición de entender que la Educación Física tiene por visión un cuerpo biomotriz en tanto máquina biológica sana y útil, tiene por misión educar al movimiento y sus técnicas, y tiene por omisión la política que implica su oficio.

En definitiva, cuando se parte de concebir al cuerpo por fuera de la política, cuando se parte de comprender que ese potencial "otro" no puede aprender por su etapa evolutiva o cuando se mide su rendimiento, se está reproduciendo ese doble proceso de psicopedagogización y de biometrización cientificista que la educación del cuerpo eugenésica legó para la Educación Física, aún hasta el presente.

Después de todo, qué cosa fuera el cuerpo sin política, tan sólo un amasijo hecho de carnes y tendones, un instrumento sin mayores pretensiones.

Movimento, Porto Alegre, v. 20, n. 4, p. 1543-1562, out./dez. de 2014. 
Educação do corpo e política: concepções de raça, eugenia e higiene na Educação Física Argentina

Resumo: A relação entre o corpo e a política é central na história das sociedades. Neste caso específico, essa relação é pensada nos discursos que fazem as políticas estatais centralizadas na Argentina sobre a Educação Física, a partir do repensar historicamente as concepções em torno da ideia de como educar os corpos para melhorar a raça. Para isso, se analisam a passagem das retóricas higienistas do século XIX e início do século XX para as interpretações eugênicas da década de 1920 e 1930, e como isso configura alguns dos argumentos das práticas disciplinares atuais.

Palavras-chave: Corpo. Política. Eugenia (ciência). Educação.

Body education and politics: conceptions of race, hygienism and eugenics in Argentinean Physical Education

Abstract: The relationship between body and politics is central in the history of societies. In this particular case, this relationship is discussed within centralized Argentinean state policies for Physical Education, focusing on the ideas of educating bodies to improve the race. We analyze the passage from hygienist rhetoric of the late nineteenth and early twentieth centuries to eugenic interpretations of the 1920s and 1930s, and how it shapes some of the current arguments of the Physical Education practices.

Keywords: Body. Politics. Eugenics. Education.

\section{REFERÊNCIAS}

AISENSTEIN, Ángela; SCHARAGRODSKY, Pablo. Tras las huellas de la Educación Física Escolar Argentina: cuerpo, género y pedagogía. 1880-1950. Buenos Aires: Prometeo, 2006.

ALEMANDRI, Próspero. Moral y deporte. Buenos Aires: Librería del Colegio, 1937.

BERTONI, Lilia Ana. Soldados, gimnastas y escolares. La escuela y la formación de la nacionalidad a fines del siglo XIX. Boletín del Instituto de Historia Argentina y Americana "Dr. Emilio Ravignani”, Buenos Aires, Tercera serie, n. 13, p.35-57, 1996.

Movimento, Porto Alegre, v. 20, n. 4, p. 1543-1562, out./dez. de 2014. 
CANESSA, Guillermo. Sarmiento y la Educación Física. Boletín de Educación Física, Santiago de Chile, v.12 , n. 49, p. 6-12, 1946.

DUSSEL, Inés, ¿Existió una pedagogía positivista? La formación de discursos pedagógicos en la segunda mitad del siglo XIX. In: PINEAU, P.; DUSSEL, I.; CARUSO, M. La escuela como máquina de educar. Buenos Aires: Paidós, 2001. p. 53-91.

ESPOSITO, Roberto. Bios: biopolítica y filosofía. Buenos Aires: Amorrortu, 2007.

FRESCO, Manuel. La Educación Física: una innovación de mi gobierno: sus fundamentos y su aplicación. Buenos Aires: Damiano, 1940.

GALAK, Eduardo. Del dicho al hecho (y viceversa): el largo trecho de la construcción del campo de la formación profesional de la Educación Física en Argentina. Legalidades, legitimidades, discursos y prácticas en la institucionalización de su oficio entre finales del siglo XIX y el primer tercio del XX. 2012. 329f. Tesis (Doctorado en Ciencias Sociales) - Universidad Nacional de La Plata, La Plata, 2012.

GALAK, Eduardo. El concepto cuerpo en Pierre Bourdieu: un análisis de sus usos, sus límites y sus potencialidades. 2010.148f. Tesis (Maestría en Educación Corporal) - Universidad Nacional de La Plata, La Plata, 2010.

GALAK, Eduardo. Herbert Spencer y la pedagogía integralista. Influencias en los inicios de la Educación Física argentina. In: GALAK, E.; VAREA, V. Cuerpo y Educación Física: perspectivas latinoamericanas para pensar la educación de los cuerpos. Buenos Aires: Biblos, 2013. p. 45-66.

GLEYSE, Jacques. La metáfora del cuerpo máquina en la educación física en Francia (1825-1935). In: SCHARAGRODSKY, P. La invención del "homo gymnasticus". fragmentos históricos sobre la educación de los cuerpos en movimiento en Occidente. Buenos Aires: Prometeo, 2011. p. 77-94.

INAUGURACIÓN de los Cursos de la Escuela Politécnica de Biotipología, Eugenesia y Medicina Social. Anales de Biotipología, Eugenesia y Medicina Social, Buenos Aires, v.2, n. 24, 1934.

KEHL, Renato. Eugenia e Eugenismo. Boletim de Eugenia, Rio de Janeiro, v. 1, n. 8, p. 1, 1929.

KINOSHITA, Carolina; PIMENTA ROCHA, Heloísa. Renato Kehl, Víctor Delfino e Alfredo Verano: circulação de ideias eugênicas entre Brasil e Argentina. In: CONGRESSO BRASILEIRO DE HISTÓRIA DA EDUCAÇÃO, 8. Cuiabá, 2013. Anais ... Cuiabá: Sociedade Brasileira de História da Educação, 2013.

LA FICHA biotipológica escolar sancionada oficialmente por la Dirección General de Escuelas de la Provincia de Buenos Aires. Anales de Biotipología, Eugenesia y Medicina Social, Buenos Aires, v.1, n. 8, 1933.

MIRANDA, Marisa; GIRÓN SIERRA, Álvaro. Cuerpo, biopolítica y control social:

Movimento, Porto Alegre, v. 20, n. 4, p. 1543-1562, out./dez. de 2014. 
Educación del cuerpo y política: concepciones de raza...

América Latina y Europa en los siglo XIX y XX, Buenos Aires: Siglo XXI, 2009.

MIRANDA, Marisa; VALLEJO, Gustavo. Darwinismo social y eugenesia en el mundo latino. Buenos Aires: Siglo XXI, 2005.

MIRANDA, Marisa; VALLEJO, Gustavo. Una historia de la eugenesia: Argentina y las redes biopolíticas internacionales. Buenos Aires: Biblos, 2012.

PENDE, Nicola. Biotipología y atletismo. Anales de Biotipología, Eugenesia y Medicina Social, Buenos Aires, v.2, n. 29, 1934.

PENDE, Nicola. Biotipología y Educación Física. Anales de Biotipología, Eugenesia y Medicina Social, Buenos Aires, v.1, n. 7, 1933.

PENDE, Nicola. Biotipología y Educación: La vigilancia médica para los ejercicios gimnásticos y deportivos en los recreos y en las colonias. Anales de Biotipología, Eugenesia y Medicina Social, Buenos Aires, v.2, n. 38, 1935.

RODRIGUEZ DOMINGUEZ, Silvio. La maza. Letra y música. Compuesta en 1979, editada por primera vez en 1982 como número 9 del álbum Unicornio.

RODRÍGUEZ, Raumar; SERÉ, Cecilia. La anatomía es el destino: la educación física y el saber del cuerpo. In: GALAK, E.; VAREA, V. Cuerpo y Educación Física: perspectivas latinoamericanas para pensar la educación de los cuerpos. Buenos Aires: Biblos, 2013. p. 87-102.

ROMERO BREST, Enrique. Algunos conceptos doctrinarios de la Educación Física, Instituto Nacional Superior de Educación Física. Buenos Aires, [s.n.], 1933.

ROMERO BREST, Enrique. Los batallones escolares: orígenes, condiciones científicas, defectos. Buenos Aires: Talleres Gráficos de la Penitenciaria Nacional, 1914.

ROMERO BREST, Enrique. Sarmiento. Revista de la Educación Física, Buenos Aires, Primera época, v.3, n. 1-6, p. 38-42, 1911.

SANCTIS, Carlos. Medicina Constitucional - Psicología y Educación Física. Anales de Biotipología, Eugenesia y Medicina Social, Buenos Aires, v.2, n. 21, 1934.

SARAVÍ RIVIERE, Jorge. Historia de la Educación Física Argentina: Siglo XIX (notas para su elaboración). Buenos Aires: Impresiones Agencia Periodística Cid, 1985.

SARMIENTO, Domingo Faustino. Obras de D. F. Sarmiento. Buenos Aires: Imprenta Mariano Moreno, 1900.

SCHARAGRODSKY, Pablo (Org.). La invención del "homo gymnasticus": Fragmentos históricos sobre la educación de los cuerpos en movimiento en Occidente. Buenos Aires: Prometeo, 2011.

SILVA, João Ítalo de Oliveira. Por uma eugenia latino-americana: Victor Delfino e

Movimento, Porto Alegre, v. 20, n. 4, p. 1543-1562, out./dez. de 2014. 
Renato Kehl. 2008. 174 f. Dissertação (Mestrado em História Política) - Faculdade de Filosofia e Ciências Humanas, UFMG, 2008.

STEPAN, Nancy. The hour of eugenics: race, gender and nation in Latin America. New York: Cornell University, 1991.

TENTI FANFANI, Emilio. El oficio del maestro: contradicciones iniciales. In: ALLIAUD, A.; DUSCHATZKY, L. (Org.). Maestros: Formación, práctica y transformación escolar. Buenos Aires: Miño y Dávila, 2011. p. 63-111.

THOMPSON, Edward. Costumbres en común. Barcelona: Crítica, 1995.

VALLEJO, Gustavo; MIRANDA, Marisa. Políticas del cuerpo: Estrategias modernas de normalización del individuo y la sociedad. Buenos Aires: Siglo XXI, 2007.

VAZ, Alexandre Fernández. Treinar o corpo, dominar a natureza: notas para uma análise do esporte com base no treinamento corporal. Cadernos CEDES, Campinas, v. 19, n. 48, p.89-108, 1999.

Auxílio de financiamento: Coordenação de Aperfeiçoamento de Pessoal de Nível Superior (CAPES). Universidade Federal de Minas Gerais. Belo Horizonte, MG

\footnotetext{
Endereço para correspondência

Calle 15 , número 80 , entre 33 y 34 ,

La Plata

C.P.: 1900

Buenos Aires, Argentina.
} 